\title{
Index Analysis Model to Enhance User Comfort in Energy Efficient Buildings
}

\author{
M. Pir Mohammadi, Abdullah Sani Ahmad*, Gurupiah Mursib, M. Moslemi Haghighi \\ Universiti Teknologi Malaysia, Skudai, Johor, Malaysia \\ *b-asani@utm.my
}

\begin{abstract}
This paper presents the research proposal initiated based on needs of high developing country like Malaysia in energy efficiency studies. The research proposal developed based on a "current" research gap to enhance design related building user comfort criteria towards efficient energy used. Research aims to develop index analysis model to enhance consideration of user comfort towards efficient energy use. The relevant objective and methodology of research in four (4) phases is presented. Firstly, it is to investigate building design attributes related to user comfort in sample size of office buildings. Secondly, it is to capture architectural design related "Energy Efficient" attributes using the same sample size of energy efficient consultants within conducting quantitative interviews. Thirdly, it is to evaluate interrelation of EE attributes versus user comfort attributes with in professional group discussion. Finally, it is to develop index analysis model in consideration of user comfort towards efficient energy used. Accordingly, each objective comply novel findings. In conclusion this paper brief proposed research steps to aims to develop index analysis model to enhance consideration of user comfort towards efficient energy use.
\end{abstract}

Keywords: Building assessment models; Building Energy efficiency; Building user comfort

\section{Introduction}

As a matter of fact, the growing global population, demographic shifts, climate change and increasing pressure on natural resources have all brought sustainability to the top of political, social and business agendas. Sustainability presents major challenges and tremendous opportunities for businesses. Energy is an important, if not the most critical factor of nation development (Agbontalor, 2007). Building construction industry practices accordingly, have realized that by investing in energy-efficiency measures, responding to changing building user requirement patterns and ensuring sustainable practices in project life cycle it is possible to move toward projects that can build and operate more efficiently and user satisfaction in more effective manner. Besides, understanding dynamic increasing loop of construction foot print in both global and local views, and also Malaysian expected housing demands (4\% per year) until 2015, it is important to aid building construction to reduce its environmental defects. These environmental defects can be categorized to "operation" based and "renovation" based (Zaimi et al. 2012).

\section{Gap in Research}

This is for more than three decades, due to the needs for sustainable, efficient and effective buildings, the buildings professionals has criticized the aspects of building function to provide the user comfort in building operations. It is reported by Volker 2004 that building users invest three times more than cost of building during the building life cycle to meet their requirements. Consequently, it forced us as researchers to think more about enhancing user requirements in a more efficient and effective manner. User comfort as one aspect of user requirements within building design has been considered. Besides it was to ensure more productive building environment. Growths of this concept are reviewed in a paper by Barry (2008). Gradually, user comfort changed fixtures of building asset management through initiating considerations of user's physical requirements. In the current scenario, energy efficient strategies in managing user requirements put forward several new techniques and new technologies in concept of "Low Energy Building" to fulfill user comfort requirements. In this regards, mainly researchers follow the technologic concept as adaptability of building HVAC system to address user physical comfort requirements in computational optimization manner in correlation with environmental changes (Barry, 2007 and 2008). In according to preliminary literature review, there is some direct discussion in journal papers about "user requirements" in new generation of building like "Intelligent Building (IB)" by Volker et al. (1997), Per Christiansson (2000), Yang and Peng (2000), Buchheit et al. (2000) and Wong, Lia, Wang (2005). But these papers didn't state how to consider these requirements in design stage and 
relatively what would be the building-like of design assessment if we consider "user requirements" in Intelligent Building (IB) design stage. Albeit, there is some building assessment approaches raised by; Preiser and Schramm (2002), So et al. (1998), Fathian, and Akhavan (2005), but all of these studies have evaluated user comfort in post-occupancy manner. Thus, there is no design enhancement cause of evaluating user requirement in building through post-occupancy manner (Barry 2008). In other words, Study observed that there is no established approach to consider user comfort in building design stage.

In addition, in previous efforts of considering user comfort, only human physical factors are focused and it has not covered basics of design aspects. On the other hand, it didn't manage to consider "energy efficiency" in design for user requirement. This is while, for instance study believes the aim of energy efficient design concept is to enhancing more sustainable, more effective building design regarding providing user requirements. Referring to literatures on social sustainability by; Omann \& Spangenberg (2002), Colantonio (2007), and Hodgson (2011), There are five (5) different principles; equitable society, diverse society, connected society and democratic society, and the society which provides a good "quality of life". In the other hand, referring to literatures there are 15 different building function (Dorasol et al., 2011) which are; Health, Safety, Security, Functionality, Efficiency, Social, Psychology, Aesthetics, Operations, Comfort, Durability, Economics, Flexibility, Accessibility, and Culture. Based on preliminary survey it observed that "User comfort" is the first priority performance for building user to fulfill the requirement of the five (5) different principles mentioned (equitable society, diverse society, connected society and democratic society, and the society which provides a good quality of life). Besides that user comfort has inter relation with Energy efficiency in building. The electricity consumption growths during 1984-2008 estimated 3 billion kilo-watt hours each year, and the main consumer is the commercial and public services that is followed by residential sectors (Energy Information Bureau (EIB)-report, 2011). Furthermore, referring to EIB report, the Residential - Electricity consumption "...is used for cooling and lighting houses, to operate appliances and machines, water heating, as well as for cooking..." That all are the user physical comfort factors. Therefore, user comfort seems to have a potential toward optimizing energy consumption in Malaysia.

To conclude, it can be argued that there is no comprehensive understanding on the dimension of user comfort in building design. Besides the current needs of Malaysia towards optimizing energy consumption have forced us to go towards consideration of "energy efficiency" in building construction and operation for future generation of building design. Accordingly, the main research question is: "How to assess the building design, to improve user comfort within efficient energy used?"

The aim of this research is to develop index analysis model to enhance consideration of user comfort towards efficient energy use in building architectural design. Having basic understanding on Building architectural design, based on aim the relevant objectives (four objectives) is planned as follow:

- To establish building architectural design attributes enhancing user comfort

- To establish building architectural design attributes enhancing "Energy Efficiency" (EE)

- To evaluate correlation of building architectural design attributes enhancing EE vs. user comfort

- To develop index analysis model in consideration of user comfort towards efficient energy used in building architectural design

The Scope of this study has several limitations. Any specific country has uniqueness of building design. By considering Malaysia as the research area, the focus is on the local culture. All physical and psychological aspects are covered in building design. Furthermore, as non-residential building is the most energy consumer type of building in Malaysia, study chosen office building as scope to focuses. Furthermore, in this study Building Architectural Design Definition defined as building design characteristic which normally is considered grounded in Architectural design. Based on that, the Building Architectural Design attributes considered as follow; lighting (natural/artificial), ventilation, acoustic, view, material texture, space, form, circulation, amenity, personality, direction, etc.

\section{Methodology}

Table 1 presents research methodology of the study in four (4) phases. Albeit, study is to follow common research methodology engaged to develop index analysis model in previous studies. 
Table 1: Research Action Plan

\begin{tabular}{|c|c|c|}
\hline Phase & Step & Activity \\
\hline \multirow[t]{3}{*}{$1^{\text {st }}$ Phase } & $\begin{array}{l}\text { Step1: } \\
\text { (Content analysis) }\end{array}$ & $\begin{array}{l}\text { literary review on user comfort criteria, (Code: Building user } \\
\text { comfort, Vehicle user comfort, Airplane user comfort) }\end{array}$ \\
\hline & $\begin{array}{l}\text { Step2: } \\
\text { (Interpretive study) }\end{array}$ & $\begin{array}{l}\text { To conduct descriptive survey (based on grounded theory } \\
\text { investigation) in a sample size of number of office buildings } \\
\text { with the aim of capturing design related comfort factors }\end{array}$ \\
\hline & $\begin{array}{l}\text { Step3: } \\
\text { (Validation) }\end{array}$ & $\begin{array}{l}\text { Finding is to be validated by academic professionals (expert } \\
\text { input/expert panel) in a brain storming meeting, using of } \\
\text { Delphi method }\end{array}$ \\
\hline \multirow[t]{3}{*}{$2^{\text {nd }}$ Phase } & $\begin{array}{l}\text { Step1: } \\
\text { (Content analysis) }\end{array}$ & $\begin{array}{l}\text { Reviewing related Energy Efficiency in office buildings (Code: } \\
\text { Low Energy Office (LEO), Zero Energy Office (ZEO), and } \\
\text { sustainable development) indicators }\end{array}$ \\
\hline & $\begin{array}{l}\text { Step2: } \\
\text { (Interpretive study) }\end{array}$ & $\begin{array}{l}\text { It is to capture architectural design attributes related to } \\
\text { "energy efficiency" in a sample size of energy efficiency } \\
\text { consultants in office building }\end{array}$ \\
\hline & $\begin{array}{l}\text { Step3: } \\
\text { (Validation) }\end{array}$ & $\begin{array}{l}\text { It is to be validated by building management professionals in } \\
\text { a brain storming session to criticize the finding (expert } \\
\text { input/expert panel) }\end{array}$ \\
\hline \multirow[t]{2}{*}{$3^{\text {rd }}$ Phase } & $\begin{array}{l}\text { Step1: } \\
\text { (Content analysis) }\end{array}$ & $\begin{array}{l}\text { Reviewing correlation analysis models (Code: Factor } \\
\text { analysis) }\end{array}$ \\
\hline & $\begin{array}{l}\text { Step2: } \\
\text { (Correlation study) }\end{array}$ & $\begin{array}{l}\text { It is to conduct Inter-relation study on Building architectural } \\
\text { design related "energy efficient" attributes vs. user comfort } \\
\text { attributes within by building management professionals in a } \\
\text { Delphi session }\end{array}$ \\
\hline \multirow[t]{2}{*}{$7^{\text {th }}$ Phase } & $\begin{array}{l}\text { Step1: } \\
\text { (Content analysis) }\end{array}$ & $\begin{array}{l}\text { Reviewing related index analysis models (Code: Building } \\
\text { Index analysis model, Building assessment models) }\end{array}$ \\
\hline & $\begin{array}{l}\text { Step2: } \\
\text { (System development } \\
\text { study) }\end{array}$ & $\begin{array}{l}\text { It is to develop the model and validate with professionals in } \\
\text { index assessment models (Green Building Index (GBI) } \\
\text { creditors) in a brain storming session, using "Synectics" } \\
\text { (expert input/expert panel) }\end{array}$ \\
\hline
\end{tabular}

\section{Results (Expected)}

This section is to clarify expected findings of the research based on introduced objectives in prior sections. To do so the expected findings are as follow:

Expected finding of Objective 1: A list of building architectural design attributes enhancing user comfort Expected finding of Objective 2: A list of building architectural design attributes enhancing "Energy Efficiency" (EE)

Expected finding of Objective 3: A matrix containing Inter-relation of building architectural design attributes enhancing EE vs. user comfort

Expected finding of Objective 4: Final Index analysis model in consideration of user comfort towards efficient energy used in building architectural design

Significant of the Study: The heading of the final Index model is the "Intellectual Property" (IP) of the research. In term of the Human Capital Development, the final model will open a new job opportunity for professionals as building assessor and building certification.

Possible Risk: In fact, there is plan to conduct interview with EE consultancies in Malaysia which may it can be hard to contact them. In the case there is possibility it change research methodology.

\section{Conclusion}

In conclusion this paper described proposed research methodology to develop building analysis model to improve user comfort within efficient energy used. Indeed, the relevant aim, objective and expected finding are addressed. 
Acknowledgement: This work was financially supported by Universiti Teknologi Malaysia, Sustainability Research Alliance (SUTRA), and International Doctoral Fellowship (IDF) under reference number UTM.J.10.01/13.14/1/128 (200907M10193).

\section{References}

Agbontalor, E. A. (2007). Overview of Biomass Energy Conservation Routes. American-Eurasian Journal of Agricultural \& Environmental Sciences, 2(6), 662-671.

So, A. T. P., Wong, A. C. W. \& Wong, K. C. (1998). A New Definition of Intelligent Buildings for Asia. Facilities, 17(12/13), 485-491.

Barry, P. H. (2007). An Evaluation of Office Productivity Measurement. Journal of Corporate Real Estate, 9(3), 144-155.

Barry, P. H. (2008). The Impact of Office Comfort on Productivity. Journal of Facilities Management, 6(1), 37-51.

Yang, J. \& Peng, H. (2000). Decision Support to the Application of Intelligent Building Technologies. Journal of Renewable Energy, 22, 67-77.

Wong, J. K. W., Lia, H. \& Wang, S. W. (2005). Intelligent Building Research: A review. Automation in Construction, 14, 143- 159.

Christiansson, P. (2000). Knowledge Representations and Information Flow in the Intelligent Building. Computing in Engineering, 604-611.

Buchheit, R. B., Garrett, Jr. J. H., Lee, S. R. \& Brahme, R. (2000). A Knowledge Discovery Framework for Civil Infrastructure: A Case Study of the Intelligent Workplace. Engineering with Computers, 16, 264-274.

Volker, H. (2004). Building as a Power Plant, (BAPP), PowerPoint presentation in Hong Kong, access at 2010.

Volker, H., Loftness, V., Mahdavi, A. \& Lee, S. (1997). An Integrated Approach to Design and Engineering of Intelligent Buildings - The Intelligent Workplace at Carnegie Mellon University. Automation in Construction, 6, 401-415.

Omann, I. \& Spangenberg, J. (2002). Assessing Social Sustain-ability: The Social Dimension of Sustainability in a Socio-Economic Scenario. Seventh Biennial Conference of the International Society for Ecological Economics. March 6-9, Sousse, Tunisia.

Colantonio, A. (2007). Social sustainability: an exploratory analysis of its definition, assessment methods metrics and tools. EIBURS Working Paper Series, 2007/01. Oxford Brooks University, Oxford Institute for Sustainable Development (OISD) - International Land Markets Group, Oxford, UK, 2007.

Hodgson, N. (2011). Social Sustainability Assessment Framework. PowerPoint presentation. http://www.istp.murdoch.edu.au/dirs/77794.html, Retrieved October, 2011.

Dorasol, N., Mohammad, I. S., Mohammed, S. D. A. H., Hamadan, N. \& Lah, N. M. I. N. (2012). post occupancy evaluation performance criteria and parameters for hospital building in Malaysia, 3rd international conference on business and economic research (3rd icber 2012) proceeding, www.internationalconference.com.my, Retrieved July, 2012.

Zaimi, M. M. A., Hasannudin, L. B., Keyvanfar, A. \& Shafaghat, A. (2012). A Proposal for Prototype Package of Green Affordable Home: Using Fast Track Wall System (April 30, 2012). OIDA International Journal of Sustainable Development, 3(12), 107-116. 